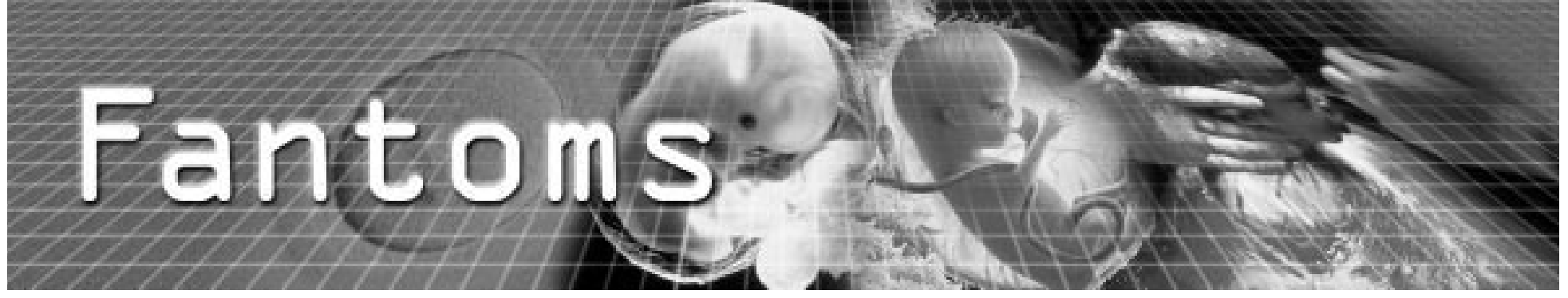

Ben Stenson, Associate editor

\section{FRIENDLY FIRE}

Hypernatraemic dehydration in breast fed infants has long been recognised as an uncommon but serious health risk in early life. Parents and other carers may not recognise that the milk intake is inadequate until severe dehydration has developed, with devastating consequences. Although this it not a new disease, reports from several centres justify concerns that it may be occurring with increased frequency. Earlier discharge from hospital after birth and increased emphasis on exclusive breast feeding may be contributors. Laing and Wong describe their experiences with this problem and review the literature, giving recommendations for the prevention, identification, and management of cases. See $p 158$

\section{RISK REDUCTION}

A confidential enquiry using methods adapted from CESDI examined 49 cases of neonatal encephalopathy cared for in the Trent Region in 1997. Suboptimal care, in which different management would reasonably be expected to have made a difference to the outcome, was found in $44 \%$ of cases of grade II and $20 \%$ of cases of grade III neonatal encephalopathy. A peripartum insult alone was felt to be responsible for the condition in $45 \%$ of cases. The confidential enquiry method allowed helpful feedback to units and may be a useful risk reduction tool for other neonatal morbidities.

See p 176

www.archdischild.com

\section{VITAL STATISTICS}

A comparison of data from the Trent Health Region in England with the whole of Denmark reveals striking differences in outcomes and clinical practice between the two areas in relation to extremely preterm infants. More liveborn infants were $<28$ weeks gestation or $<1000 \mathrm{~g}$ in Trent than in Denmark (Trent 4.88 per 1000 livebirths, Denmark 3.31 per 1000 livebirths). Despite more antenatal steroids, Trent infants had higher CRIB scores, were twice as likely to be ventilated (Trent $87.9 \%$, Denmark $40 \%$ ), and were more likely to die (Trent $42.3 \%$, Denmark 35\%). Survival adjusted for disease severity was similar. The authors speculate that these differences in reproductive health might be attributable to social disadvantage. It is difficult to separate out effects that may result from different postnatal care practices. Comparative data for other health regions in the UK would be interesting. Members of the public might be surprised to learn that the recording of outcome data is not mandatory in the NHS, nor is there an established infrastructure to enable pooling and analysis of such data. Field, Manktelow, and Draper call for core funding for data collection and analysis. See pp 163 and 172

\section{NEONATAL THYROID DISORDERS}

Neonatal thyroid disorders in preterm and term infants are reviewed by OgilvyStewart. Studies of thyroid function in preterm infants reveal a complex situation that is not yet fully understood. Although some infants appear to be hypothyroxinaemic and this can be correlated to measures of adverse outcome, it is not clear whether treatment is beneficial. Under some circumstances it may be harmful. Further research is required before treatment can be recommended. The existence, location, and size of the thyroid gland can be assessed in newborn infants using ultrasound scanning. Perry et al describe normative data for healthy, appropriately grown term infants.

See pp 165 and 209

\section{UNDER PRESSURE}

Early intervention for posthaemorrhagic hydrocephalus does not improve outcome, but there is no objective measure of when later intervention should begin. Maertzdorf and colleagues performed regular cerebrospinal fluid (CSF) drainage through subcutaneous reservoirs in infants with progressive ventricular dilatation. They measured CSF pressure and cerebral blood flow velocity. Although there was no correlation between the two in cross sectional data, cerebral blood flow velocity usually improved when drainage of CSF lowered the CSF pressure to less than $6 \mathrm{cmH}_{2} \mathrm{O}$. They suggest that this pressure may be a suitable cut off for CSF drainage. This approach requires the insertion of a CSF reservoir and it remains to be seen whether it influences outcome.

See p 185

\section{RHESUS REQUIREMENTS}

The neonatal mortality from rhesus isoimmunisation is low and few infants require treatment. Among 81000 infants liveborn in South Thames in 1999-2000, 26 infants received treatment for rhesus isoimmunisation and none died. Exchange transfusion was required by seven infants and top up transfusion by seven.

See $\mathrm{p} 202$ 